\title{
The relevance of identity style and professional identity to academic commitment and academic achievement in a higher education setting
}

\author{
F. Ruric Vogel ${ }^{\mathrm{a}}$ and Salomé Human-Vogel ${ }^{\mathrm{b}}$ \\ ${ }^{a}$ ENGAGE, Faculty of Engineering, Built Environment, and Information Technology \\ University of Pretoria, Pretoria, South Africa; \\ ${ }^{\mathrm{b}}$ Department of Educational Psychology, University of Pretoria, Pretoria, South Africa
}

\begin{abstract}
Student retention remains an on-going concern for higher education institutions worldwide. In the present study we examine the predictive utility of identity styles, professional identity and academic commitment to academic achievement. We asked 120 second year students in the profession of engineering in an augmented degree programme to complete the Identity Styles Inventory-3, the Engineering Identity Factors Inventory, and the Academic Commitment Scale. We found that a normative identity style predicted professional engineering identity and meaningfulness, which predicted the participants' investments in their studies. Additionally, a diffuse-avoidant identity style negatively predicted professional identity, meaningfulness and satisfaction, which provides empirical evidence of the contribution of identity to academic commitment. None of the variables we studied predicted academic achievement. Our findings are relevant given current debates on access, equity and decolonisation in higher education, because it suggests that students' sense of identity largely influences whether they feel a sense of belonging at university. Although identity styles and meaningfulness are not significant direct predictors of academic achievement, they probably do have an indirect effect on academic achievement through their direct influence on investment.
\end{abstract}

\section{Keywords}

identity styles; academic commitment; professional identity; engineering; meaningfulness 


\section{Introduction}

Student success in higher education is an on-going concern for universities and colleges globally. In South Africa, many students in the post-school education and training sector do not manage to complete their education in the minimum time (DHET, 2017). Student access and success rates vary in terms of race and gender (CHE, 2010), with white and Indian/Asian students having higher success rates than other population groups. The success rate for contact learning students are generally higher than for distance education (DHET, 2017). Some students appear to be better prepared to adapt to the demands of higher education. Particularly, the role of student engagement to student success remains a well-explored priority for higher education scholars (Kinzie \& Kuh, 2017; Tinto, 2006-2007). Also, the contribution of institutional factors to student success (such as policies, educational climate, and facilities) and student-related factors (such as ability, self-efficacy, age and gender, and sense of belonging) are vibrant areas of enquiry in higher education (Barbera, Berkshire, Boronat, \& Kennedy, 2017; Geisinger \& Raman, 2013; Van den Bogaard, 2012). Related to institutional factors are issues of curriculum transformation and decolonisation as possible factors that influence success rates of marginalised groups, in particular in higher education (Hall \& Tandon, 2017). In addition to general attrition rates in higher education, we also see specific problems related to supplying countries' needs for professionals in the science, technology, engineering, and mathematics (STEM) fields (Du Toit \& Roodt, 2009; Fisher, 2011; Rasool 2014), which represents the context in which the current study took place.

The reasons for student attrition in higher education are complex. This applies in South Africa (Scott, Yeld \& Hendry, 2007), the United States (National Center for Education Statistics, 2005) and many countries in Europe, South America, and Asia (OECD 2014). Generally, studies of attrition in higher education focus on the first year experience (Willcoxon, Cotter and Joy, 2011) but different factors influence success in the second year of study. Although institutional and systemic factors constrain students' ability to complete their studies, we know that intrapersonal factors also affect students' decision to abandon their studies (Human-Vogel \& Rabe, 2015). Marra, Rodgers, Shen, and Bogue (2012) point out that both academic and non-academic factors (such as belonging) influence students' decision to abandon their studies. Marra et al., (2012) argue that non-academic factors such as identity-related considerations exert a stronger influence on students' decision to continue to study than academic factors. These factors can be influenced through personal and professional development and good teaching practices. 
In the present study, we draw on Berzonsky's $(1988,1990)$ social-cognitive framework of identity processing styles (i.e. informational, normative, and diffuse-avoidant). Information-oriented individuals tend to self-reflect and show problem-focused coping. They are systematic in their decision-making, conscientious, open to experience, and able to achieve an identity (Berzonsky, 1990; Berzonsky \& Kuk, 2005; Berzonsky, Cieciuch, Duriez, \& Soenens, 2011). Individuals with a normative identity style deal with identity conflicts rather automatically by conforming to the expectations and prescriptions of significant others. They tend to be agreeable and conscientious, with a stable, foreclosed sense of self, but they also have a strong need for structure and cognitive closure (Berzonsky, 1990; Berzonsky \& Kuk, 2005; Berzonsky et al., 2011). Those with a diffuse-avoidant style procrastinate and tend to be reactive to situational demands and incentives. They lack self-awareness, have low levels of conscientiousness, and lack educational persistence, amongst other traits (Berzonsky, 1990; Berzonsky \& Kuk, 2005; Berzonsky et al., 2011). Szabo, Ward, and Fletcher (2016) report that Berzonsky's identity processing framework can be used reliably and validly for examining identity development of immigrants during cultural transition.

Although identity processing style influences students' academic performance (Berzonsky \& Kuk, 2005; Hejazi, Shahraray, Farsinejad, \& Asgary, 2009), it does not usually predict academic performance, probably because the association is mediated by factors such as self-discipline and effective planning (Berzonsky \& Kuk, 2005). Our aim in the present study was to explore professional identity and academic commitment as mediators of the hypothesised theoretical relationship between identity style and academic performance.

We expected both an informational and a normative identity style to be positively associated with academic commitment. As Berzonsky et al. (2011) indicate, an informational identity style is associated with high levels of commitment, and a normative identity style is associated with a sense of purpose as well as high levels of commitment. By contrast, we expected those with a diffuse-avoidant style (as suggested by Berzonsky et al., 2011) to experience less satisfaction with their studies, to find less meaning in their studies, and to avoid making sizable investments in their success.

Berzonsky and Kuk (2005) report a moderate relationship between the informational and diffuse-avoidant identity processing styles on the one hand, and academic achievement on the other. They found that a normative identity style was not related to academic achievement. Hejazi et al., (2009) found that identity styles mediated by academic selfefficacy predict $20 \%$ of the variance in academic achievement. We are aware of only one study in South Africa, conducted by Seabi and Payne (2013), which claimed that identity 
styles were unrelated to academic achievement, but nevertheless reported that informationaloriented students seemed to perform better than diffuse-avoidant students. Given the uncertainty about any association between identity style and academic achievement, we think it is important to consider how identity style may influence how students approach their studies, rather than to attempt to predict academic achievement directly on the basis of identity style. Given the cultural variation of South Africa's general population (Adams, Van de Vijver, \& De Bruin, 2012), we acknowledge that our findings may be influenced by the cultural orientation of our participants.

One of the moderators we have already alluded to, is that of academic commitment (Human-Vogel \& Rabe, 2015), conceptualised as students' long-term persistence with their studies. In a prior study among engineering students, we found that students' level of investment was a predictor of their semester mark, and could be predicted by domain-specific self-efficacy and the personal meaningfulness of their studies (Vogel \& Human-Vogel, 2016). These findings support earlier studies that focus on commitment as a predictor of academic success (Kluger \& Koslowsky, 1988) and college student attrition (Geyer, Brannon \& Shearon, 1987). Research has shown that commitment to an academic major and satisfaction with faculty interactions are a significant predictor of grade point averages in second year students (Graunke \& Woosley, 2005). Recently, Human-Vogel and Rabe (2015) reported that students who had a clearly differentiated sense of self and were satisfied with their studies had a higher level of commitment to their studies. In addition, these authors also showed that students who set learning goals were more likely to be meaningfully committed to their studies, were more satisfied with their studies, and tended to invest more time and effort in their studies.

A second moderator that we introduced into the present study relates to the issue of professional identity development, which is related to students' major and career goals (Jones, Tendhar, \& Paretti 2015; Meyers, Ohland, Pawley, Silliman, \& Smith, 2012). Students who see themselves as developing professionals are more likely to find their studies meaningful, to take their studies seriously (i.e. to be committed), to be more satisfied with their studies, and to invest in their future as prospective engineers.

As a theoretical concept, professional identity is neither clearly delineated nor well understood in the literature (Trede, Macklin \& Bridges 2012). It appears to involve a developmental process that generally occurs in stages (Baxter Magolda, 2004; Thornton \& Nardi, 1975) and seems to consist of an individual and a social dimension (Dehing, Jochems \& Baartman 2013), which occurs within a particular sociocultural context where sense of 
belonging to a particular community (for example, the engineering community) is paramount (Tonso 2006). Nadelson, McGuire, Davis, Farid, Hardy and Hsu et al., (2015, p. 5) define professional identity as the "attributes, skills, knowledge, beliefs, practices, and principles, which are representative of professionals within a profession". Professional identity development requires students to adopt and internalize the attitudes, skills and behaviours of a particular profession, such as engineering, in the current study. In their research on engineering identity, Meyers et al., (2012) found that students frequently identified with three general factors, (i) making competent design decisions, (ii) the ability to work with others, and (iii) taking responsibility for their actions. Also, a sense of belonging to the engineering institution and organizational recognition were coupled to engineering identity. There is also evidence to suggest that engineering identity development is gendered ( $\mathrm{Du}$ 2006). For example, Cech (2015) found that female engineering students value social consciousness more and technological leadership less than their male counterparts.

Based on our review of the literature, our objective was to examine whether identityprocessing style is associated with academic commitment and a professional engineering identity. Given the multitude of individual, institutional and systemic factors that moderate and mediate academic achievement outcomes, we expected identity styles to be significantly associated with academic commitment, along with professional engineering identity. We expected professional engineering identity to have an additional strengthening effect on the relationship between personal identity and academic commitment. We utilised a nonexperimental, correlational design to explore the relationship between our variables, and a series of multiple linear regression models to test our hypotheses (Christensen, Johnson, \& Turner 2015).

The present study contributes to the literature on factors associated with student retention, with a specific focus on South African students in their second year in an augmented curriculum programme.

\section{Research Methodology}

\section{Participants}

The participants were enrolled in their second year of an extended B.Eng. programme consisting of several augmented modules that run in conjunction with the main modules of the B.Eng. degree. The augmented modules consist of one lecture and three discussion classes a week (Grayson 2010). We chose to study second year students based on the assumption that they will have had time to adjust to the university environment, and also 
because it has been suggested that their success is influenced by different factors than those that have an impact on first year students (Graunke \& Woosley, 2005). Convenience sampling was used to collect data in the Materials Science augmented module. Because participants do not write a formal examination in their augmented modules, we used the final semester mark as a proxy for academic achievement, consisting of written assignments (20\%), class tests (30\%), and two semester tests (50\%).

The study was approved by the Faculty's Ethics Review Board. Participation was voluntary with full informed consent for the completion of the questionnaire and the use of participants' final semester marks. Respondents completed the questionnaires, which included biographical variables, the Identity Styles Inventory (Berzonsky 1992), the Academic Commitment Scale (Human-Vogel \& Rabe 2015), and the Engineering Identity Factors Inventory, adapted from the Engineering Identity Factors Survey (Meyers et al., 2012). The questionnaire was administered during an additional Material Science lecture in the seventh week of the fourth semester. Of the 175 students registered for the Additional Materials Science module, 120 participants (29 female and 91 male students) completed the questionnaire (mean age 20,3; SD - 1.00), which represents a response rate of $68.6 \%$. Of those, 56 were White, 54 Black, seven were Indian, and two were of mixed race. There was also one Arabic mother-tongue participant. Of the total sample, 47 participants spoke an indigenous African language, 40 participants spoke Afrikaans, and 27 spoke English. The remaining five spoke either Arabic, French, Portuguese, or Polish. One respondent did not indicate his or her home language.

\section{Measures}

\section{Identity Styles Inventory}

Identity style was measured using the Identity Styles Inventory (ISI-3) (Berzonsky 1992). Participants responded to 40 items on a five-point Likert-type scale ranging from 1 (not at all like me) to 5 (very much like me). The inventory consists of three continuous scales, namely the Informational Style Scale (I've spent a great deal of time thinking seriously about what I should do with my life; 11 items; $\alpha=.65$ ), the Normative Style Scale (I prefer to deal with situations where I can rely on social norms and standards; 9 items; $\alpha=.67$ ), and the Diffuseavoidant Style Scale (I'm not really thinking about my future now; it's still a long way off; 10 items; $\alpha=.74$ ). We did not use the fourth scale (i.e. the Commitment Scale) because our focus was on the identity processing styles as predictors. The alpha coefficients for the 
identity style scales used in the current study compare well with those found in the literature (for example, Berzonsky \& Kuk 2005).

\section{Academic Commitment Scale}

To measure participants' level of academic commitment, the Academic Commitment Scale (ACS) (Human-Vogel \& Rabe 2015) was used. Participants responded to 30 items on a sixpoint Likert scale ranging from 1 (strongly disagree) to 6 (strongly agree). The ACS consists of five scales, namely Level of Commitment (I want to continue with my studies; five items; $\alpha$ $=.80$ ), Satisfaction (My studies give me a great deal of satisfaction; eight items; $\alpha=.88$ ), Quality of Alternatives (There are better things in life than studying; three items; $\alpha=.70$ ), Investment (I spend a lot of time on my studies; five items; $\alpha=.86$ ), and Meaningfulness (My studies fulfil me; nine items; $\alpha=.86$ ). The alpha coefficient for the full scale in the current study was .90 , which compared well with the values reported by Human-Vogel and Rabe (2015).

\section{Engineering Identity Factors Inventory}

Participants responded to 29 items of the Engineering Identity Factors Inventory (EIFI), adapted from the Engineering Identity Factors Survey (Meyers et al., 2012). The first item refers to identification with being an engineer (Do you consider yourself an engineer?). The remaining 28 items involve factors associated with the engineering profession (for example, being able to make competent design decisions). We converted the binary response options (yes/no) in the original questionnaire to a six-point Likert scale, ranging from 1 (strongly disagree) to 6 (strongly agree). The alpha coefficient for the EIFI was .87, which we regarded as acceptable for further analysis.

\section{Results}

\section{Descriptive statistics and t-test}

Using an independent samples t-test, we found no significant differences between males and females, ethnicities, and different language groups for any of the study variables. The descriptive statistics of the Identity Style Inventory, the total score of the Engineering Identity Factors Inventory, and the Academic Commitment Scale appear in Table 1. 
Table 1. Descriptive statistics of the Identity Styles Inventory, Engineering Identity

Factors Inventory, and the Academic Commitment Scale

\begin{tabular}{llllllll}
\hline Variable & $\mathrm{N}$ & Min & Max & $\mathrm{M}$ & SD & \multicolumn{2}{l}{ Skewness } \\
\cline { 6 - 8 } & & & & & & Statistic & Std Error \\
\hline Informational Style & 120 & 2.27 & 4.82 & 3.64 & .47 & -.26 & .22 \\
Normative Style & 120 & 1.67 & 5.00 & 3.63 & .56 & -.55 & .22 \\
Diffuse-avoidant & 120 & 1.10 & 4.50 & 2.57 & .62 & .14 & .22 \\
Commitment & 120 & 2.70 & 4.90 & 4.03 & .49 & -.41 & .22 \\
Level of Commitment & 120 & 3.40 & 6.00 & 5.65 & .48 & -2.13 & .22 \\
Satisfaction & 120 & 1.25 & 3.75 & 2.99 & .47 & -.80 & .22 \\
Quality of Alternatives & 120 & 1.00 & 5.33 & 2.66 & 1.14 & .41 & .22 \\
Investment & 120 & 2.20 & 6.00 & 4.80 & .82 & -.52 & .22 \\
Meaningfulness & 120 & 1.89 & 6.00 & 4.38 & .78 & -.56 & .22 \\
Engineering Identity & 118 & 3.61 & 6.00 & 5.10 & .45 & -.67 & .22 \\
\hline
\end{tabular}

\section{Correlational analysis}

Results of a zero-order correlational analysis of the Identity Styles Inventory (ISI-3), the Academic Commitment Scale (ACS), the Engineering Identity Factors Inventory (EIFI), and Academic Achievement appear in Table 2.

Table 2. Pearson correlations between identity style, academic commitment, engineering identity, and academic achievement $(\mathrm{N}=120)$

\begin{tabular}{|c|c|c|c|c|c|c|c|c|c|c|c|}
\hline Measure & Variables & 1 & 2 & 3 & 4 & 5 & 6 & 7 & 8 & 9 & 10 \\
\hline \multirow[t]{3}{*}{$\overline{\text { Identity Styles }}$} & Informational & 1 & .126 & -.175 & .087 & .153 & .176 & $.241^{\text {*** }}$ & -.026 & .108 & .007 \\
\hline & Normative & & 1 & .053 & .088 & $.194^{*}$ & $.325^{* *}$ & $.243^{* *}$ & .037 & $.233^{*}$ & .027 \\
\hline & Diffuse & & & 1 & $-.306^{* *}$ & $-.299^{* *}$ & $-.286^{* *}$ & $-.325^{* *}$ & $.428^{* *}$ & $-.271^{* *}$ & -.037 \\
\hline \multirow{6}{*}{$\begin{array}{l}\text { Academic } \\
\text { Commitment }\end{array}$} & Level of & & & & 1 & $.578^{* *}$ & $.563^{* *}$ & $.393^{* *}$ & $-.217^{*}$ & $.285^{* *}$ & .053 \\
\hline & Commitment & & & & & & & & & & \\
\hline & Satisfaction & & & & & 1 & $.636^{* *}$ & $.540^{*}$ & $-.334^{* *}$ & $.266^{* *}$ & .151 \\
\hline & Meaningfulness & & & & & & 1 & $.452^{* *}$ & $-.392^{* *}$ & $.348^{* *}$ & .052 \\
\hline & Investment & & & & & & & 1 & -.097 & $.323^{* *}$ & .171 \\
\hline & $\begin{array}{l}\text { Quality of } \\
\text { Alternatives }\end{array}$ & & & & & & & & 1 & -.111 & .071 \\
\hline Engineering & Engineering & & & & & & & & & 1 & -.004 \\
\hline Identity & Identity Factors & & & & & & & & & & \\
\hline $\begin{array}{l}\text { Academic } \\
\text { Achievement }\end{array}$ & Final Mark & & & & & & & & & & 1 \\
\hline
\end{tabular}

As we expected, academic achievement did not correlate significantly with any of the study variables. Also, the correlational pattern we obtained for identity processing styles 
supports previous South African research by Seabi and Payne (2013), but contradicts Berzonsky and Kuk's (2005) pattern of findings.

The pattern of intra-correlations for the ACS followed the expected direction and was significant $(\mathrm{p}=.000)$ for all variables, except Quality of Alternatives $(\mathrm{p}=.05)$ as also reported by Human-Vogel and Rabe (2015). This result provides additional construct-related evidence for the validity of the ACS. The three identity processing styles were not significantly associated with one another, which is also in line with previous findings (Berzonsky \& Kuk, 2005).

We obtained an interesting pattern of correlations for the three identity styles with the $A C S$. The informational identity style did not correlate significantly with any of the ACS scales, except for Investment ( $\mathrm{r}=.241 ; \mathrm{p}=.008)$. On the other hand, the normative identity style correlated significantly with Satisfaction $(\mathrm{r}=.194 ; \mathrm{p}=.033)$, Meaningfulness $(\mathrm{r}=.325$; $\mathrm{p}=.000)$, and Investment $(\mathrm{r}=.243 ; \mathrm{p}=.000)$, but not with Level of Commitment or Quality of Alternatives. The diffuse-avoidant identity style showed a significant but negative correlation with Level of Commitment $(r=-.306 ; p=.001)$, Satisfaction $(r=-.299 ; p=.001)$, Meaningfulness $(r=-.286 ; \mathrm{p}=.002)$ and Investment $(\mathrm{r}=-.325 ; \mathrm{p}=.000)$, and a positive correlation with Quality of Alternatives $(r=.428 ; \mathrm{p}=.000)$.

The total score of the EIFI was significantly correlated with Level of Commitment (r $=.285 ; \mathrm{p}=.002)$, Satisfaction with Studies $(\mathrm{r}=.266 ; \mathrm{p}=.003)$, Meaningfulness $(\mathrm{r}=.348 ; \mathrm{p}=$ $.000)$ and Investment $(r=.323 ; \mathrm{p}=.000)$, but not with Quality of Alternatives. The normative identity style was significantly positively correlated with the total score of the EIFI $(\mathrm{r}=.233$; $\mathrm{p}=.011$ ), whereas the diffuse-avoidant identity style was negatively correlated with the total score of the EIFI ( $\mathrm{r}=-.271 ; \mathrm{p}=.003)$. However, no significant correlation for the informational identity style with the total score of the EIFI was obtained.

\section{Regression analysis}

Next, we tested three research questions: (i) Are identity styles predictors of meaningful academic commitment? (ii) Do identity styles contribute to the development of a professional engineering identity? (iii) Does professional engineering identity contribute to the strengthening of academic commitment? To examine these research questions, we formulated a series of separate models to test our null hypotheses (see Table 3). 
Table 3. Models to test the null hypotheses

Model 1: Are Meaningfulness, Satisfaction and Quality of Alternatives predictors of Investment?

Model 2: Do personal identity styles influence Meaningfulness?

Model 3: Do personal identity styles influence Satisfaction?

Model 4: Do personal identity styles influence Quality of Alternatives?

Model 5: Does engineering identity moderate the relationship between personal identity and Meaningfulness, Satisfaction and Quality of Alternatives?

We examined each model separately in a series of multiple linear regressions. With Model 1, we wanted to ascertain which of the academic commitment variables would predict investment. Thus, we specified the dependent variable as Investment, and we entered Meaningfulness (Block 1), Satisfaction (Block 2) and Quality of Alternatives (Block 3) as independent variables. The results indicated a significant model $\left(\mathrm{R}^{2}=0.33 ; \mathrm{F}=18.9 ; \mathrm{p}=\right.$ .000) with significant amounts of variation in the dependent variable being explained only by $(\mathrm{t}=2.2 ; \mathrm{p}=.03)$ and Satisfaction $(\mathrm{t}=4.5 ; \mathrm{p}=.000)$.

In the next three models (Models 2 - 5), we examined the commitment variables in terms of identity styles. In Model 2, we specified Meaningfulness as the dependent variable and Informational Identity Style (Block 1), Normative Identity Style (Block 2), and Diffuseavoidant Identity Style (block 3), as independent variables. This resulted in a significant model $\left(\mathrm{R}^{2}=0.20 ; \mathrm{F}=14.42 ; \mathrm{p}=.000\right)$ with significant predictors being a Normative Identity Style $(\mathrm{t}=4.12 ; \mathrm{p}=.000)$, and a Diffuse-avoidant Identity Style $(\mathrm{t}=-3.67 ; \mathrm{p}=.000)$.

We followed the same steps to examine the independent variables with Satisfaction (Model 3) and Quality of Alternatives (Model 4) as dependent variables. The results for Model 3 indicated that Satisfaction was significantly predicted inversely $\left(R^{2}=0.09 ; F=\right.$ $11.55 ; \mathrm{p}=.001)$ by a diffuse-avoidant identity style only $(\mathrm{t}=-3.40 ; \mathrm{p}=.001)$, with all the other predictors failing to achieve significance. The results for Model 4 indicated that Quality of Alternatives was also predicted significantly $\left(\mathrm{R}^{2}=0.18 ; \mathrm{F}=26.4 ; \mathrm{p}=.000\right)$ by a diffuseavoidant identity style only $(\mathrm{t}=5.14 ; \mathrm{p}=.000)$. The pattern of results obtained suggests that the normative and diffuse-avoidant identity styles follow different pathways in the way they may exert an influence on academic commitment.

Next we proceeded to test our moderator hypothesis in Model 5. Because the normative and diffuse-avoidant identity styles are not related, and considering the different 
pathways through which they predict Meaningfulness, Satisfaction and Quality of Alternatives, we decided to test them separately (using two steps) in the moderator models reported below. In step one, Meaningfulness was specified as the independent variable, with a normative identity style, a diffuse-avoidant identity style and a professional engineering identity as the three predictors. A significant model was obtained $\left(\mathrm{R}^{2}=0.24 ; \mathrm{F}=12.07 ; \mathrm{p}=\right.$ .000), with all three predictors being significant. In the second step, the independent variable was specified as Satisfaction, and the predictors were specified as a diffuse-avoidant identity style and a professional engineering identity. Again, a significant model was obtained $\left(R^{2}=\right.$ $0.13 ; F=8.45 ; p=.000$ ) in which both predictors (Diffuse: $t=-2.72 ; p=.007$; professional engineering identity: $t=2.23 ; p=.03$ ) were significant. Human-Vogel (2008) suggested that meaningfulness maintains commitment in the absence of satisfaction. Our sample demonstrated relatively high meaningfulness $(x=4.4 ; s d=.78)$, and low satisfaction with their studies $(x=3.0 ; s d=.47)$, indicating that it is possible to experience high meaning and low satisfaction simultaneously.

We then examined whether identity style would also predict satisfaction with studies, as was the case with meaningful commitment. Our results demonstrated that only a diffuseavoidant identity style predicted satisfaction inversely $\left(R^{2}=0.159 ; F=5.43 ; p=.000\right)$.

The combined model is presented in Figure 1 below.

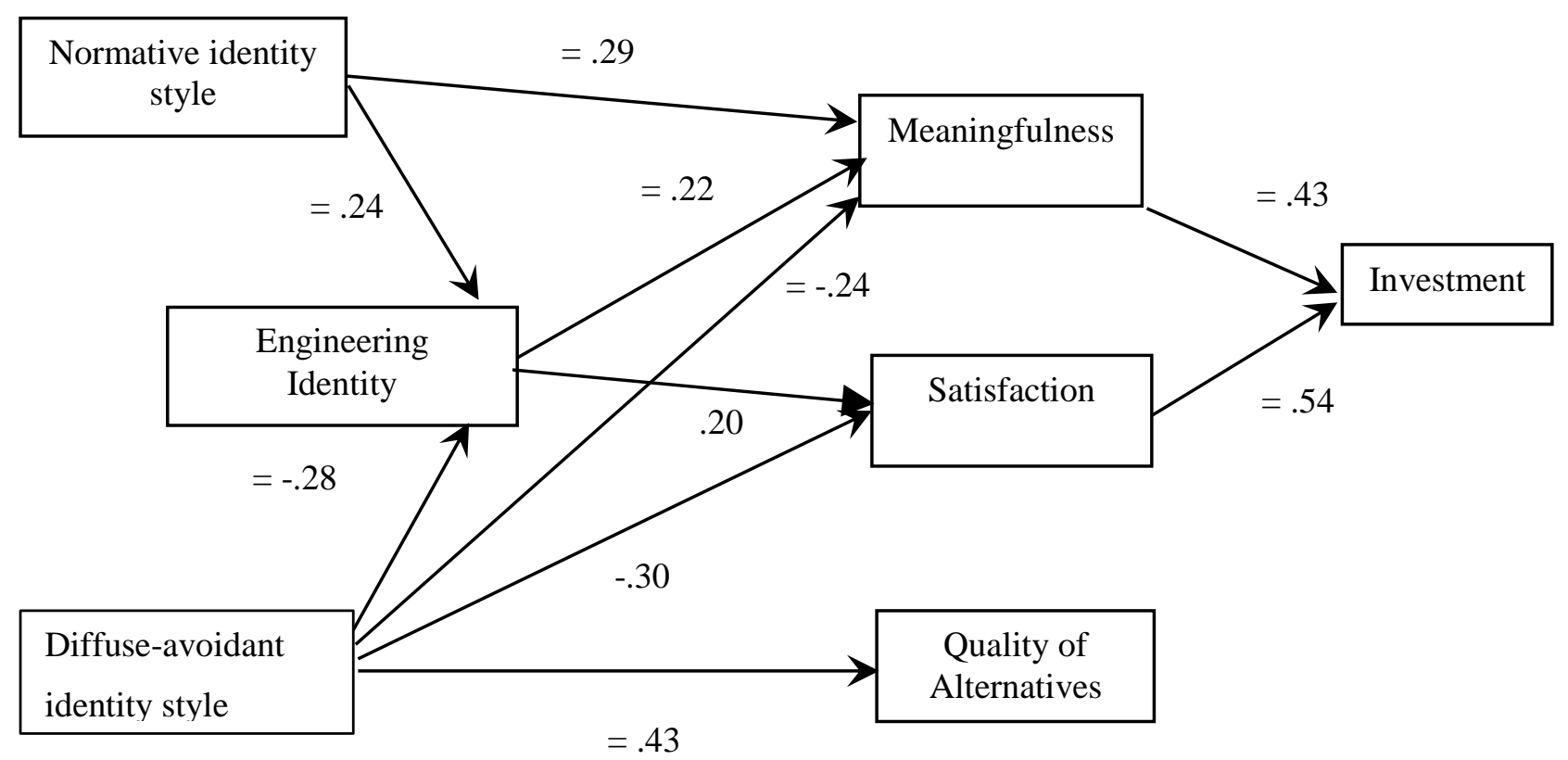

Figure 1. Combined model for identity style, engineering identity, and commitment 


\section{Discussion}

Understanding how to maximise the retention of higher education students in general, and students studying towards a professional degree such as engineering in particular, is an important part of a strategy to supply a country's economy with highly skilled graduates. The solution often posited is that if higher education students put in effort and time to achieve their goals, success must automatically follow. As we said earlier, numerous personal, contextual and systemic factors conspire to create a situation whereby most students who enter higher education, never complete it.

In the present study, our objective was to examine academic commitment as a possible pathway through which identity styles lead to observed differences in academic achievement, reported in the literature (Berzonsky \& Kuk, 2005; Seabi \& Payne, 2013). We were also interested to know whether the development of a professional engineering identity would strengthen students' academic commitment and predict better investment. The study was guided by the general assumption that student attributes generally contribute significantly to student engagement and academic success (Willcoxon et al. 2011; Kahu 2013).

As with Seabi and Payne (2013), our results did not show any significant correlation between academic achievement and identity style. Also, academic achievement and academic commitment was not correlated significantly. Because investment of time and effort is usually related to academic achievement (Kahu 2013), we wondered whether our measurement of academic achievement may have contributed to this result. We decided to conduct a post hoc analysis by considering the Pearson correlations between academic commitment and our components of academic achievement, namely (i) class tests, (ii) semester tests, and (iii) assignments.

The Pearson correlations showed a small, but significant correlation $(\mathrm{r}=.188, \mathrm{p}=$ .04) of investment with the average semester test mark, but not the other two components. At least three factors may help to explain this result. First, the weight of the semester test mark is $50 \%$ of students' total mark, so students typically study harder (that is, invest more) for semester tests. Second, assignments carry $20 \%$ of the weight of the total mark and give students an opportunity to work in groups, resulting in a less reliable indicator of individual achievement. Third, even though students have to pass modules in both the mainstream and augmented modules to obtain their degree, anecdotal evidence suggests that students spend less time on the augmented modules than they do on mainstream modules, as they perceived the augmented modules to be less important. As our results also indicate, investment in our 
sample was predicted significantly, both by the extent to which students felt their studies were satisfying, and by the extent to which they thought their studies were meaningful. It is possible that the augmented modules may be perceived as less meaningful than the mainstream modules.

Considering the relationship between identity style and academic commitment, as measured by Meaningfulness, Satisfaction and Quality of Alternatives, a number of interesting findings emerged. Consistent with Berzonsky and Kuk's (2005) observation that students with a diffuse-avoidant identity style are least prepared for demands of higher education, we found that having a diffuse-avoidant identity style made students significantly more vulnerable to experiencing a lack of meaning and lower satisfaction in their studies. Students also appeared to be significantly more likely to be distracted by high quality alternatives. Students with a diffuse-avoidant identity style in our sample were also less likely to develop a professional engineering identity. Because professional identity refers to who students want to become in the future (Clarke, Hyde \& Drennan, 2013), we conclude that students with a diffuse-identity style are both unprepared for academic studies, and also undecided about their future career. Not surprisingly, students with a normative identity style are more likely to have a developed professional engineering identity, and to experience their studies as meaningful. Clarke et al., (2013) argue that individual identity is one of the components of professional identity, so our findings suggest that, at least for professional degree studies in STEM fields, a better understanding of the development of students' individual and professional identity seems warranted.

A noticeable pattern that emerged in our findings was that Satisfaction and Meaningfulness significantly predicted Investment, but they offer different pathways to success, depending on whether students have a normative or diffuse-avoidant identity style. Considering that students with a normative identity style tend to have a clear sense of purpose and direction (Berzonsky \& Kuk, 2005), this finding is not surprising. Meaning is often associated with having goals and a sense of purpose (Weinstein, Ryan and Deci, 2012). Furthermore, having a normative or diffuse-avoidant identity style also means that meaningfulness is mediated to some extent by a student's engineering identity albeit in opposite directions. A normative identity style also means that experiences of satisfaction are not necessarily an important motivator for these students except when engineering identity acts as a mediator. This is an important distinction, because it is generally agreed that satisfied students are less likely to drop out of higher degree studies (O'Keefe, 2013). 
Meaning, or a lack thereof, was important for students with either a normative or a diffuse-avoidant identity style. People are naturally oriented toward experiences and activities that they experience as meaningful, and tend to abandon activities that lack a sense of meaning. Therefore, students may remain committed to experiences that they find meaningful, even though such experiences are not always associated with high satisfaction. Certainly, higher education studies require a great deal of strenuous effort, so it stands to reason that students do not enter these fields expecting only to have fun and satisfaction all the time. Our results indicate that for students with a normative identity style, finding their studies meaningful is a significant predictor of their investment, whereas satisfaction did not influence this prediction unless mediated by engineering identity. The development of a professional identity thus added a further positive influence to this pathway. Practically, higher education institutions that offer higher education degrees can exert some influence over dropout rates by offering targeted personal and professional identity development initiatives in addition to the usual academic development programmes. In addition, knowing that some students selected for professional degrees may have a diffuse-avoidant identity style could help institutions to structure early intervention strategies that offer the necessary career counselling, personal development and academic support initiatives for these students. In a developing country, such as South Africa - with its struggling economy and high unemployment levels, especially among the youth (Yu 2013) - it is possible that many students enter engineering degrees because of the perception that they will be offered favourable employment opportunities in a competitive labour market, and not necessarily out of personal interest. In terms of personal development, higher education institutions can support students to develop personally and professionally, not just academically.

We acknowledge that our interpretations are limited by the fact that we did not attempt to explore or account for the possible influence of cultural orientation on identity style. Previous research indicates that adolescents in three different cultural contexts (American, Czech and, Finnish) draw on the same pattern of self-elements regardless of cultural context (Berzonsky, Macek, Nurmi, 2003). Granted that these three cultural contexts represent the global north, and there is little evidence of the transferability of these findings to countries in the global south, we agree with Lee, Beckert and Goodrich (2010) and Low et al (2005), and more recently Szabo et al (2016), that western models of identity development, and particularly Berzonsky's social-cognitive model of identity processing styles can be applied reliably and validly to non-western populations. Nevertheless, there would be some value in future research to establish whether the patterns reported by Berzonsky et al. (2003) 
also hold in South Africa, where students tend to be influenced by parental and societal views (Low, Akande \& Hill 2005).

The current study demonstrated that a normative identity style and a concomitant professional identity are associated with satisfaction and meaningfulness regarding participants' studies and, in turn, significantly predicted investment. Investment is usually associated with time and effort put into studies, but it also implies perseverance, which recently has been referred to as grittiness, or grit. Grit refers to perseverance and focus on long-term goals (Von Culin, Tsukayama \& Duckworth 2014), and may determine the size of students investment and subsequent attainment of long-term goals. Intuitively, there appears to be significant construct overlap between academic commitment and grit, because both is described in terms of long-term goal attainment. Future research to distinguish these two constructs could therefore prove valuable to our understanding of the personal factors that influence student success.

With its emphasis on the second year of study, the current study contributes to the literature on the understanding of non-academic factors that contribute to student attrition (Marra et al., 2012), and indirectly also to the literature on sense of belonging, which plays an important role in students success and the ability of higher education institutions to retain their students until they complete their degree. This study provides further supporting evidence of the importance of identity style in forming and maintaining meaningful commitment. Identity-relevant commitments play a structuring and orienting role in goal pursuit, and understanding these enhance understanding of the role that identity style plays in goal selection. Goal pursuit also helps us to understand how to influence academic commitment in students. Regarding the retention of students in their second year, the current study emphasises the importance of developing intervention strategies particularly in extended and augmented degree programmes to help students with personal and professional identity development. Our results suggest that it is important for faculty and lecturers to engender a professional identity as part of the curriculum to encourage students to develop a sense of belonging in their chosen profession.

\section{References}

Adams, B. G., \& Van de Vijver, F. J. R., \& de Bruin, G. P. (2012). Identity in South Africa: Examining self-descriptions across ethnic groups. International Journal of Intercultural Relations 36(3): 377-388. 
Barbera, S. A., Berkshire, S. D., Boronat, C. B., \& Kennedy, M. H. (2017). Review of Undergraduate Student Retention and Graduation Since 2010: Patterns, Predictions, and Recommendations for 2020. Journal of College Student Retention 0(0): 1-24. doi.org/10.1177/1521025117738233

Baxter Magolda, M. B. (2004). Evolution of a constructivist conceptualization of epistemological reflection. Educational Psychologist 39(1): 31-42.

Berzonsky, M. D. (1988). Self-theorists, identity status, and social cognition. In D. K. Lapsley \& F. C. Power (Eds.), Self, ego, and identity: Integrative approaches (pp. 243-262). New York: Springer.

Berzonsky, M. D. (1990). Self-construction over the life-span: A process perspective on identity formation. In G. J. Neimeyer \& R. A. Neimeyer (Eds.), Advances in personal construct psychology, Vol. 1 (pp.155-186). Greenwich, CT: JAI.

Berzonsky, M. D. (1992). Identity Style Inventory (ISI3): Revised version. Unpublished measure, State University of New York, Cortland, NY.

Berzonsky, M. D., \& Kuk, L. S. (2005). Identity style, psychosocial maturity, and academic performance. Personality and Individual Differences 39(1): 235-247.

Berzonsky, M. D., Macek, P., \& Nurmi, J.-E. (2003). Interrelationships Among Identity Process, Content, and Structure: A Cross-Cultural Investigation. Journal of Adolescent Research 18(2): 112-130.

Berzonsky, M. D., Cieciuch, J. Duriez, B., \& Soenens. B. (2011). The how and what of identity formation: Associations between identity styles and value orientations. Personality and Individual Differences 50(2): 295-299.

Cech, E. (2015). Engineers and engineeresses? Self-conceptions and the development of gendered professional identities. Sociological Perspectives 58(1): 56-77.

Christensen, L. B., Johnson, R. B., \& Turner, L. A. (2015). Research methods, Design, and Analysis. (12 ${ }^{\text {th }}$ Ed., Global Edition). Boston: Pearson.

Clarke, M., Hyde, A., \& Drennan, J. (2013). Professional identity in higher education. In B. M. Kehm \& U. Teichler (Eds.), The academic profession in Europe: New tasks and new challenges (pp.7-22). Dordrecht: Springer.

Council on Higher Education (CHE). (2010). Higher Education Monitor: Access and throughput in South African Higher Education: Three case studies. Pretoria: Council on Higher Education. 
Dehing, F., Jochems, W., \& Baartman, L. (2013). Development of an engineering identity in the Engineering curriculum in Dutch higher education: An exploratory study from the teaching staff perspective. European Journal of Engineering Education 38(1): 1-10.

Department of Higher Education and Training (DHET). (2017). Statistics on post-school Education and Training in South Africa: 2015. Pretoria: Department of Higher Education and Training.

Du, X. Y. (2006). Gendered practices of constructing an engineering identity in a problembased learning environment. European Journal of Engineering Education 31(1): 3542.

Du Toit, R., \& Roodt, J. (2009). Engineering professionals. In J. Erasmus \& M. Breier (Eds.), Skills shortages in South Africa: Case studies of key professions, (pp.75-112). Cape Town: HSRC Press.

Fisher, G. (2011). Improving throughput in the Engineering Bachelor's degree: Report to the Engineering Council of South Africa. Glen Fisher Consulting.

Geisinger, B. N., \& Raman, D. R. (2013). Why they leave: Understanding student attrition from engineering majors. International Journal of Engineering Education 29(4): 914-925.

Geyer, P. D., Brannon, Y. S. \& Shearon, R. W. (1987). The prediction of students' satisfaction with community college vocational training. Journal of Psychology 121(6): 591-597.

Graunke, S.S., \& Woosley, S. A. (2005). An exploration of the factors that affect the academic success of college sophomores. College Student Journal 39(2): 367-376.

Grayson, D. J. (2010). Design of the Engineering Augmented Degree Programme at the University of Pretoria. Cape Town: ASSAf Mind the Gap Forum. http://www.assaf.co.za/stem-mind-the-gap-forum.pdf (accessed 7 April 2016).

Hejazi, E., Shahraray, M. M., \& Asgary, A. (2009). Identity styles and academic achievement: Mediating role of academic self-efficacy. Social Psychology of Education 12(1): 123-135.

Hall, B. L., \& Tandon, R. (2017). Decolonization of knowledge, epistemicide, participatory research and higher education. Research for All, 1(1), 6 - 9 .

Human-Vogel, S. (2008). The role of identity in self-regulation: When do students cope and when do they commit? Journal of Psychology in Africa 18(1): 115-122. 
Human-Vogel, S., \& Rabe, P. (2015). Measuring self-differentiation and academic commitment in university students: A case study of education and engineering students. South African Journal of Psychology 45(1): 60 -70.

Jones, B. D., Tendhar, C., \& Paretti, M. C. (2015). The Effects of Students' Course Perceptions on Their Domain Identification, Motivational Beliefs, and Goals. Journal of Career Development 43(5): 1- 15.

Kahu, E. R. (2013). Framing student engagement in higher education. Studies in Higher Education 38(5): 758-773.

Kinzie, J., \& Kuh, G. (2017). Reframing Student Success in College: Advancing Know-What and Know-How. Change: The Magazine of Higher Learning 49(3): 19 -27.

Kluger, A. N., \& Koslowsky, M. (1988). Commitment and academic success. Social Behavior and Personality 16(2): 121-125.

Lee, C., Beckert, T. E., \& Goodrich, T. R. (2010). The Relationship Between Individualistic, Collectivistic, and Transitional Cultural Value Orientations and Adolescents' Autonomy and Identity Status. Journal of Youth and Adolescence 39(8): 882-893.

Low, J. M., Akande, D., \& Hill, C. (2005). A cross-cultural comparison of identity development: South Africa and the United States. Identity: An International Journal of Theory and Research 5(4): 303-314.

Marra, R.M., Rodgers, K. A., Shen, D., \& Bogue, B. (2012). Leaving Engineering: A multiyear single institution study. Journal of Engineering Education 101(1): 6-27.

Meyers, K. L., Ohland, M. W., Pawley, A. P., Silliman, S. E., \& Smith, K. A. (2012). Factors relating to engineering identity. Global Journal of Engineering Education 14(1): $119-131$.

Nadelson, L.S., McGuire, S. P., Davis, K. A., Farid, A., Hardy, K. K., Hsu, Y. C., et al., (2017). Am I a STEM professional? Documenting STEM student professional identity development. Studies in Higher Education 42(4): 701-720.

National Center for Education Statistics. (2005). College persistence on the rise? Changes in 5 year degree completion and postsecondary persistence rates between 1994 and 2000. In NCES Statistical Analysis Report, 2005-156. Washington, DC: U.S. Department of Education, Office of Educational Research and Improvement.

O'Keefe, P. (2013). A sense of belonging: Improving student retention. College Student Journal 47(4): 605-613.

Organization for Economic Co-operation and Development. (2014). Education at a glance. OECD indicators. OECD Publishing. doi: 10.1787/eag-2014-en 
Rasool, H. (2014). Top 100 occupations in high demand list. Draft Discussion Document for Advisory Group, Department of Higher Education and Training, Pretoria.

Scott, I., Yeld, N., \& Hendry, J. (2007). A case for improving teaching and learning in South African higher education. Higher Education Monitor. Pretoria: Council on Higher Education.

Seabi, J. \& Payne, J. (2013). Effects of identity processing styles on academic achievement of first year university students. International Journal of Educational Management 27(3): 311-322.

Szabo, A., Ward, C., \& Fletcher, G. J. O. (2016). Identity Processing Styles During Cultural Transition: Construct and Measurement. Journal of Cross-Cultural Psychology 47(4): 483-507.

Thornton, R. \& Nardi, P. (1975). The dynamics of role acquisition. American Journal of Sociology 80(4): 870-885.

Tinto, V. (2006-2007). Research and Practice of Student Retention: What Next? Journal of College Retention 8(1): 1-19.

Tonso, K. L. (2006). Student engineers and engineer identity: Campus engineer identities as figured world. Cultural Studies of Science Education 1(2): 273-307.

Trede, F., Macklin, R., \& Bridges, D. (2012). Professional identity development: A review of the higher education literature. Studies in Higher Education 37(6): 1023-1040.

Van den Bogaard, M. (2012). Explaining student success in engineering education at Delft University of Technology: A literature synthesis. European Journal of Engineering Education 37(1): 59-82.

Vogel, F. R. \& Human-Vogel, S. (2016). Academic commitment and self-efficacy as predictors of academic achievement in additional materials science. Higher Education Research and Development 35(6): 1298-1310.

Von Culin, K. R., Tsukayama, E., \& Duckworth, A. L. (2014). Unpacking grit: Motivational correlates of perseverance and passion for long-term goals. Journal of Positive Psychology 9(4): 306-312.

Weinstein, N., Ryan, R. M., \& Deci, E. L. (2012). Motivation, meaning and wellness. In. P. T. P. Wong Ed.) The human quest for meaning: Theories, research and applications, (pp. 196-239). New York, NY: Routledge. 
Willcoxson, L., Cotter, J., \& Joy, S. (2011). Beyond the first-year experience: The impact on attrition of students' experiences throughout undergraduate degree studies in six diverse universities. Studies in Higher Education 36(3): 331-352.

Yu, D. (2013). Youth unemployment in South Africa since 2000 revisited. Stellenbosch Economic Working Papers 04/13. Working paper of the Department of Economics and the Bureau for Economic Research at the University of Stellenbosch. http://www.sun.ac.za (accessed 24 March 2016). 